\title{
Linking Ground Forest Inventory and NDVI in Mapping above Ground Carbon Stock in Kasane Forest Reserve, Botswana
}

\author{
Lesika Basalumi ${ }^{1,2 *}$, Charles Joseph Kilawe1, Ernest William Mauya ${ }^{3}$ \\ ${ }^{1}$ Department of Ecosystems and Conservation, Sokoine University of Agriculture, Morogoro, Tanzania \\ ${ }^{2}$ Department of Forestry and Range Resources, Gaborone, Botswana \\ ${ }^{3}$ Forest Engineering and Wood Science, Sokoine University of Agriculture, Morogoro, Tanzania \\ Email: ${ }^{\star}$ lesikabasalumi@yahoo.com
}

How to cite this paper: Basalumi, L., Kilawe, C.J. and Mauya, E.W. (2018). Linking Ground Forest Inventory and NDVI in Mapping above Ground Carbon Stock in Kasane Forest Reserve, Botswana. Open Journal of Forestry, 8, 429-438.

https://doi.org/10.4236/ojf.2018.83027

Received: January 18, 2018

Accepted: July 28, 2018

Published: July 31, 2018

Copyright $(92018$ by authors and Scientific Research Publishing Inc. This work is licensed under the Creative Commons Attribution International License (CC BY 4.0).

http://creativecommons.org/licenses/by/4.0/

\begin{abstract}
Quantification of the above ground carbon stock (AGC) is important in sustainable forest management and policy advice on climate change mitigation. Traditional ground vegetation survey methods have been used to provide data for estimation of AGC stock but constrained by inadequate time and often too costly. Remote sensing when combined with few ground collected data has the potential of improving forest resource assessment even though this opportunity has not well been utilised. In this study, we mapped AGC through combination of ground survey data collected from 51 permanent sapling plots with Normalized Difference Vegetation Index (NDVI) derived from Landsat 5 Thematic Mapper image. Linkage of the two data sources was made during a training stage of supervised classification. The overall classification accuracy was $98 \%$, suggesting that reliable estimate of AGC for a large area can be made through combination of medium resolution satellite imagery and few samples from the ground.
\end{abstract}

\section{Keywords \\ Carbon, Miombo Woodlands, NDVI}

\section{Introduction}

Forests play an important role in the global carbon cycle. They can either be a source of atmospheric carbon in the case of biomass combustion, or a sink in the case of carbon sequestration from growth. The global forest pool has been estimated to contain about $80 \%$ of the aboveground, and $40 \%$ of the belowground 
carbon stored in terrestrial ecosystems (Dixon et al., 1994). About 43\% of global forests are found in the tropics, of which $42 \%$ are located in arid and semi-arid areas (dry forests, woodlands and rangelands) (Brown et al., 2005). In general, dry forests have lower biomass stocks than wetter forests. However, the more widespread coverage of dry forests make them a considerable terrestrial carbon store (Glenday, 2008).

The estimation of carbon in forest woody biomass has importance in global climate mitigation policy and processes as well as for sustainable planning of resource conservation, utilization and management. The conventional way of ground vegetation survey involves an intensive field work data collection. It is an expensive procedure requiring more resources such as manpower and equipment (forest inventory instruments and vehicles). Field work data collection is time consuming hence exacerbating monetary expenditure for the whole process in the form of subsistence and overtime allowances (Hall et al., 2002). Remote sensing overcomes most of challenges encountered in ground field surveys. When combined with few ground collected data, remote sensing has the potential of improving forest resource management, even though this opportunity has not well been utilised (Wulder \& Franklin, 2003). Advances in remote sensing techniques allow track changes in real time and pinpoint hotspots and specific areas of concern, providing critical knowledge that was not possible prior to this technological development. Furthermore, advantages of remote sensing become more pronounced as the region to be inventoried gets larger or more remote or both.

This study link ground data collected through ground vegetation survey and satellite imagery in order to map AGC of Kasane Forest Reserve in 2011. KFR is among the most important biodiversity in Botswana, but it's constantly under threat of being depleted due to human activities such as township expansion, infrastructure development, fuelwood collection, and recurrent wildfires.

\section{Materials and Methods}

\subsection{Study Area}

The study area is Kasane Forest Reserve (KFR) located within the Chobe District of Botswana and its total area is 75,040 ha (Figure 1). KFR contains Miombo woodland species such as Brachystegia species, Baikiaea plurijuga, Pterocarpus angolensis, Colophospermum mopane and Burkea africana. It lies south of Kasane Township, Kazungula and Lesoma which are adjacent villages stretching eastward to the Zimbabwe border and westwards to Chobe National Park. The villagers depend mainly on agriculture and livestock for their livelihood (mixed crop-livestock). KFR is used for grazing purposes, collection of firewood, pole for building as well as other non-timber forest products (NTFP). The estimated average annual temperature in Kasane is $22.9^{\circ} \mathrm{C}$ in a year while the average rainfall is $643 \mathrm{~mm}$.

The estimation of forest carbon in the Chobe Forest Reserves in Botswana has 


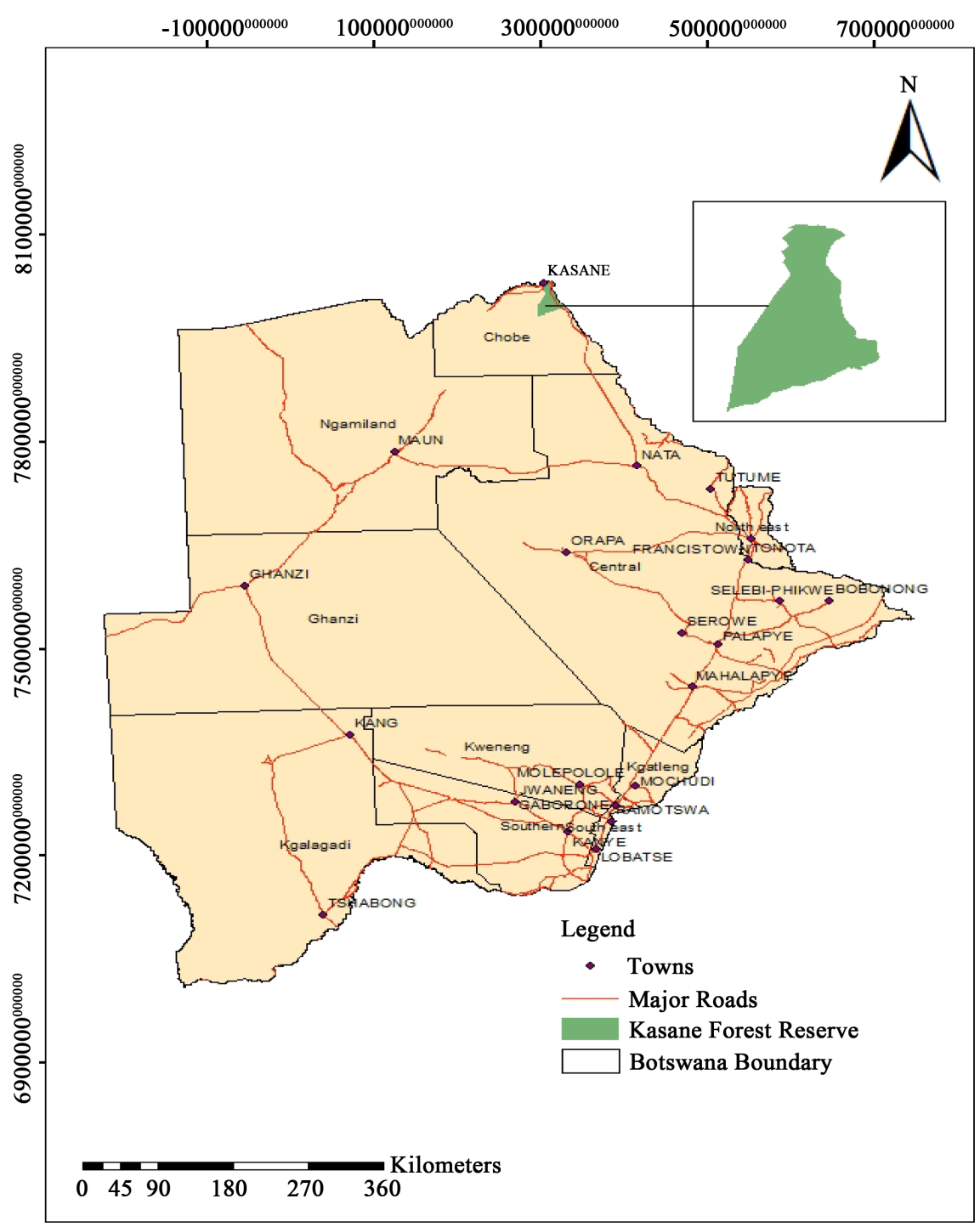

Figure 1. Location of Kasane forest in Chobe district.

in the past been neglected with only a few small scale project level forest inventories conducted. These inventories relied on using a small number of field plots mainly due to high unsustainable costs of field based inventories thus not capturing a true representation of the state of forest carbon in the forest reserve. The lack of carbon stocks information has made it difficult to monitor emissions changes therefore, presented a challenge to Botswana in meeting international reporting obligations and making sound decision for sustainable forest management.

\subsection{Data Collection and Analysis}

\subsubsection{Ground Vegetation Data}

Vegetation data was collected from 51 permanent plots by the Department of Forestry and Range Resources inventory in 2011 (Figure 2). The sampling plots were set in 1992 and were to be monitored every after 10 years. A hand held 


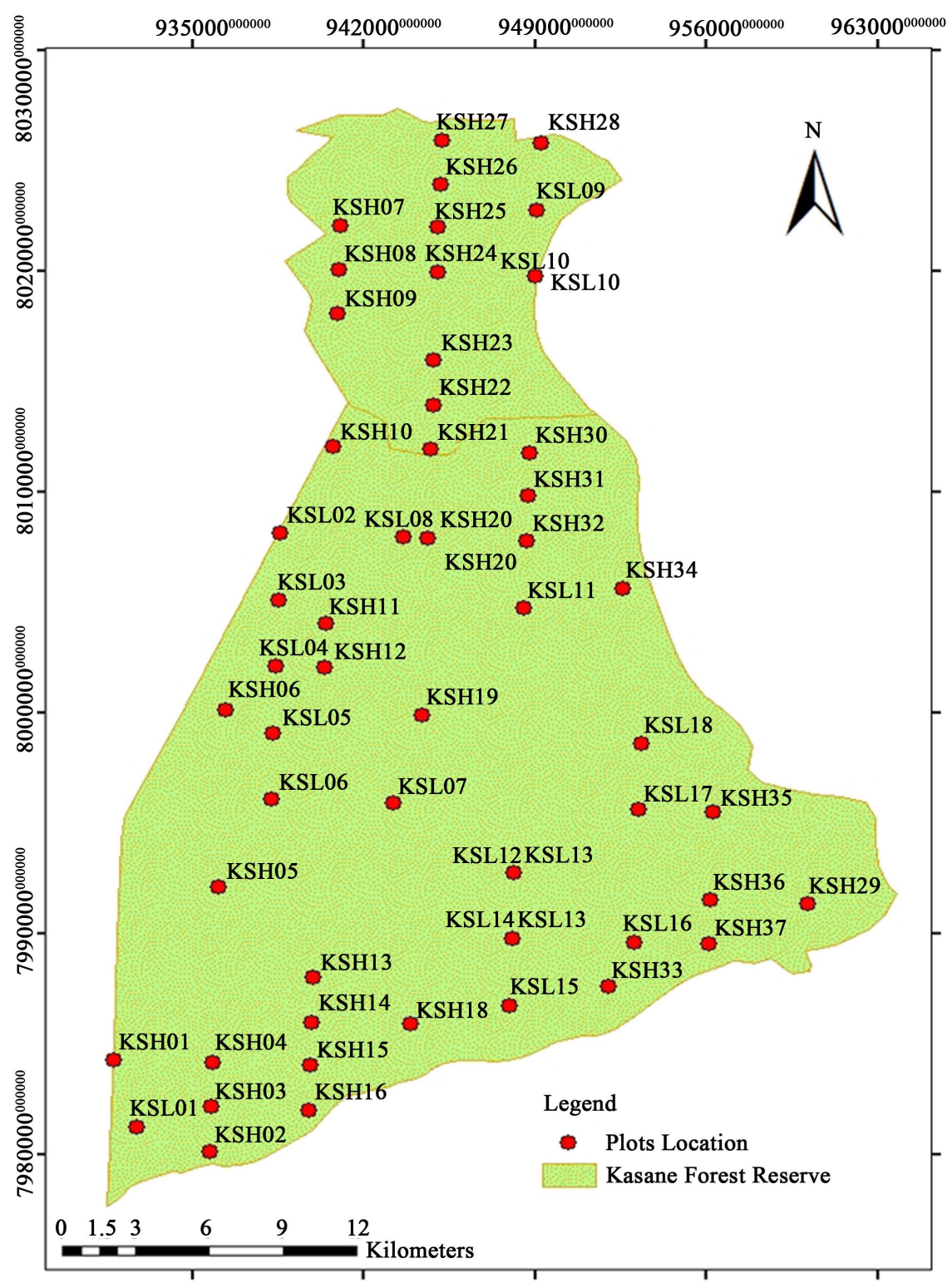

Figure 2. Location of permanent sample plot within Kasane forest reserve.

Global Positioning System (GPS) facilitated orienting direction to the next plots. Concentric plot (National Forest Resources Monitoring and Assessment of Tanzania-NAFORMA, 2010) was adopted and used in this study. To ease the counting process, each sample plot was sub-divided into two sub-plots (concentric plots) of radius $8 \mathrm{~m}$ and $30 \mathrm{~m}$ located $300 \mathrm{~m}$ apart. In the $8 \mathrm{~m}$ circle, all trees of diameter at breast height (dbh $1.3 \mathrm{~m}$ ) of 5 to $19.9 \mathrm{~cm}$ were measured while for $30 \mathrm{~m}$ circle trees of $20 \mathrm{~cm}$ and above were measured for $\mathrm{dbh}$. Tree diameters were measured using veneer caliper and/or diameter tape while tree heights were measured using Suunto hypsometer.

Vegetation data was analysed for biomass through allometric equations for Miombo woodlands with coefficient of determination $\left(\mathrm{R}^{2}\right)$ of 0.95 (Malimbwi et al., 2016). The equation is as follows: 


$$
\mathrm{B}=0.1027 \times \mathrm{dbh}^{2.4798}
$$

where:

$\mathrm{B}=$ biomass $(\mathrm{kg})$.

$\mathrm{dbh}=$ diameter at breast height $(\mathrm{cm})$.

Above ground carbon was converted to carbon using a factor of 0.49 (National Forest Resource Monitoring and Assessment of Tanzania-NAFORMA, 2010).

\subsubsection{Spatial Data}

A $30 \mathrm{~m}$ resolution Landsat 5 Thematic Mapper (TM) satellite image of 18th April, 2011 was downloaded from USGS Earth explorer, Path 173 and row 73. The April image was acquired because it has minimum cloud cover and coincides well with the duration when ground vegetation survey was conducted. Normalized Difference Vegetation Index (NDVI) was derived from the Landsat Image using Equation (2) below. NDVI was selected because is the most commonly used metrics for predicting and estimating different biophysical parameters such as forests canopy, biomass, volume and carbon (Vafaei et al., 2018).

$$
\mathrm{NDVI}=\frac{(\mathrm{NIR}-\mathrm{R})}{(\mathrm{NIR}+\mathrm{R})}
$$

where:

NIR is near infra-red band value.

$\mathrm{R}$ is Red band value.

\section{Results and Discussions}

\subsection{The NDVI for Kasane Forest Reserve}

In this study, the NDVI map values ranged from -0.00083317 to 0.773484 (Figure 3). NDVI play an important role in monitoring variations in vegetation, high NDVI values reflects dense and or healthier vegetation while low NDVI represents less or no vegetation (Matsushita et al., 2007). The results of NDVI values in the south west are high compared to other parts of the forest due to fewer disturbances from fire and human activities and relatively better climatic condition.

\subsection{Linking NDVI and Ground Inventory to Map above Ground Carbon Stock}

Linkage between ground survey and satellite imagery was made through a training stage of supervised classification. Firstly, the average carbon stock and NDVI for each permanent plot was obtained. In the process, 50\% of AGC was matched with NDVI and training samples obtained (Table 1). It was ensured that the training samples covered all strata observed in the image. Before any classification was made, Pairwise correlation was performed to find out the degree of association between AGC and NDVI data (Figure 4). The association was found to be good $(r>0.7)$, allowing the usage of one variable above the other. 


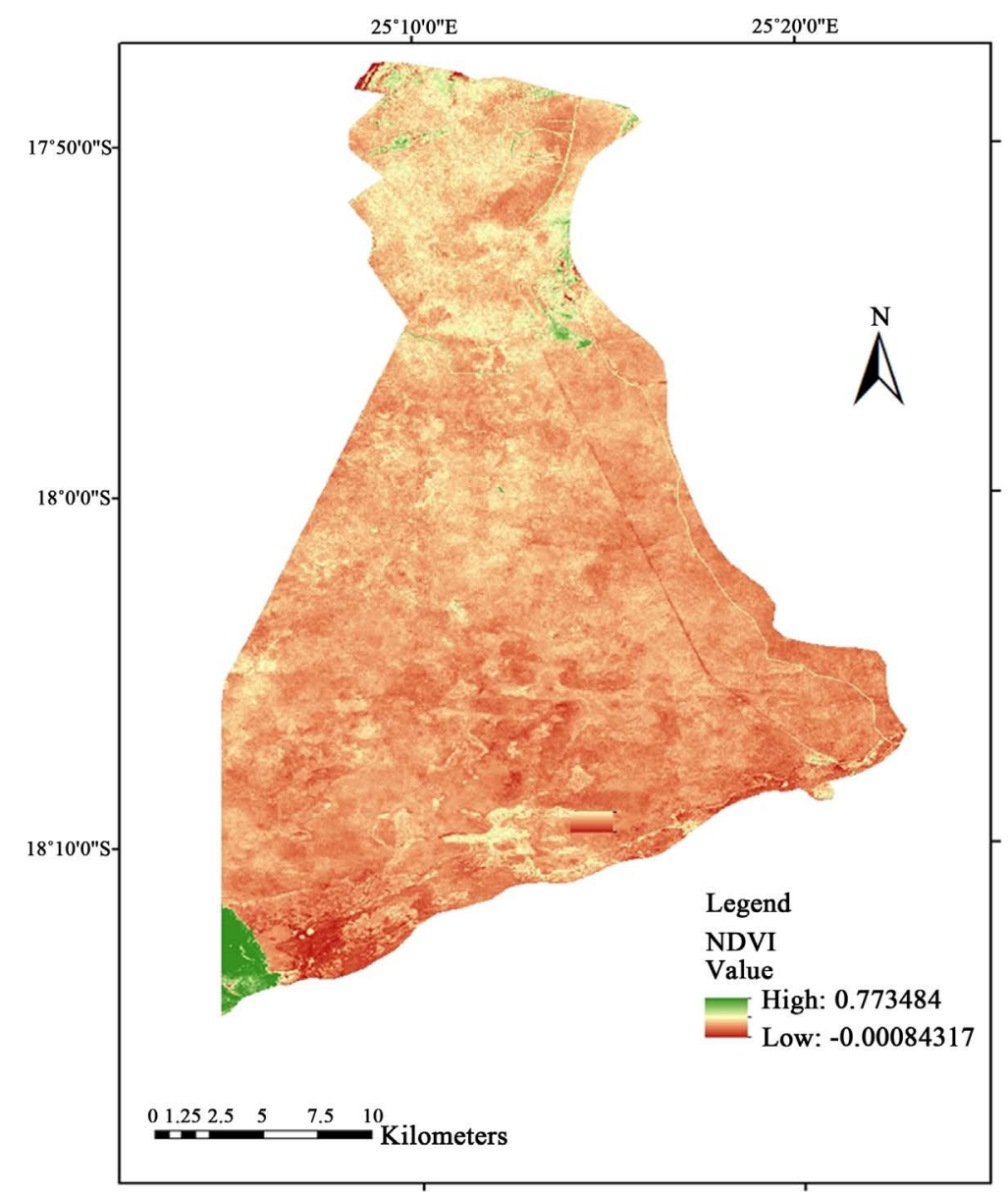

Figure 3. The NDVI map for Kasane forest reserve.

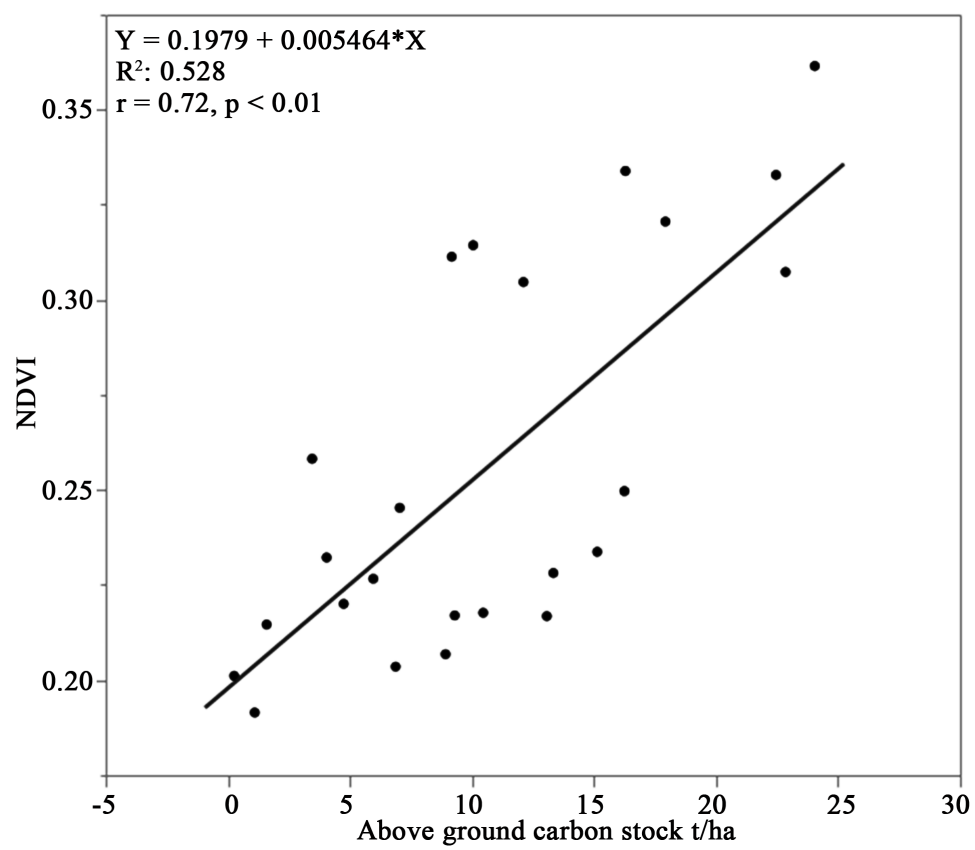

Figure 4. Scatter plot of Normalized Difference Vegetation Index (NDVI) and Above Ground Carbon stock (AGC). 
Table 1. NDVI and ABC at a plot level.

\begin{tabular}{|c|c|c|c|}
\hline PSP ID & Biomass $\mathrm{t} / \mathrm{ha}$ & Carbon $\mathrm{t} / \mathrm{ha}$ & NDVI Values \\
\hline 1 & 7.05 & 3.45 & 0.26 \\
\hline 4 & 45.83 & 22.46 & 0.33 \\
\hline 5 & 18.97 & 9.29 & 0.22 \\
\hline 6 & 12.16 & 5.96 & 0.23 \\
\hline 7 & 20.51 & 10.05 & 0.31 \\
\hline 8 & 33.15 & 16.25 & 0.25 \\
\hline 9 & 0.53 & 0.26 & 0.20 \\
\hline 11 & 2.25 & 1.10 & 0.19 \\
\hline 14 & 49.07 & 24.04 & 0.36 \\
\hline 17 & 46.63 & 22.85 & 0.31 \\
\hline 18 & 24.71 & 12.11 & 0.30 \\
\hline 19 & 18.20 & 8.92 & 0.21 \\
\hline 20 & 8.26 & 4.05 & 0.23 \\
\hline 22 & 36.58 & 17.92 & 0.32 \\
\hline 23 & 27.21 & 13.33 & 0.23 \\
\hline 24 & 21.35 & 10.46 & 0.22 \\
\hline 26 & 3.24 & 1.59 & 0.21 \\
\hline 27 & 26.66 & 13.07 & 0.22 \\
\hline 30 & 33.24 & 16.29 & 0.33 \\
\hline 32 & 9.68 & 4.74 & 0.22 \\
\hline 35 & 30.88 & 15.13 & 0.23 \\
\hline 36 & 14.37 & 7.04 & 0.25 \\
\hline 37 & 14.03 & 6.87 & 0.20 \\
\hline
\end{tabular}

Where: NDVI: Normalized Difference Vegetation Index, ABC: Above Biomass Carbon.

\subsection{Large Scale Mapping of above Ground Carbon Stock}

Supervised classification was performed using Support Vector Machine algorithms in ENVI 5.1 to produce AGC map of the entire forest (Figure 5). For convenience, four classes were generated: 1) $\leq 20 \mathrm{t} / \mathrm{ha}$; 2) $21-40 \mathrm{t} / \mathrm{ha}$; 3) $41-60$ $\mathrm{t} / \mathrm{ha}$; and 4) $>61 \mathrm{t} / \mathrm{ha}$. Generally, results indicated that most of the forest reserve area has the carbon of $0-10 \mathrm{t} / \mathrm{ha}$. The total sum of carbon for class 1 is 116.53 $\mathrm{t} /$ ha, class 2 is $194.49 \mathrm{t} / \mathrm{ha}$, class 3 is $227.04 \mathrm{t} / \mathrm{ha}$ and class 4 is $208.23 \mathrm{t} / \mathrm{ha}$ ). Carbon Class 3 has the highest while the lowest being class 1 whereas the overall carbon for all the classes was $746.29 \mathrm{t} / \mathrm{ha}$. The variation is because of some Eco zones having high carbon due to dense and healthy vegetation, moderate carbon 


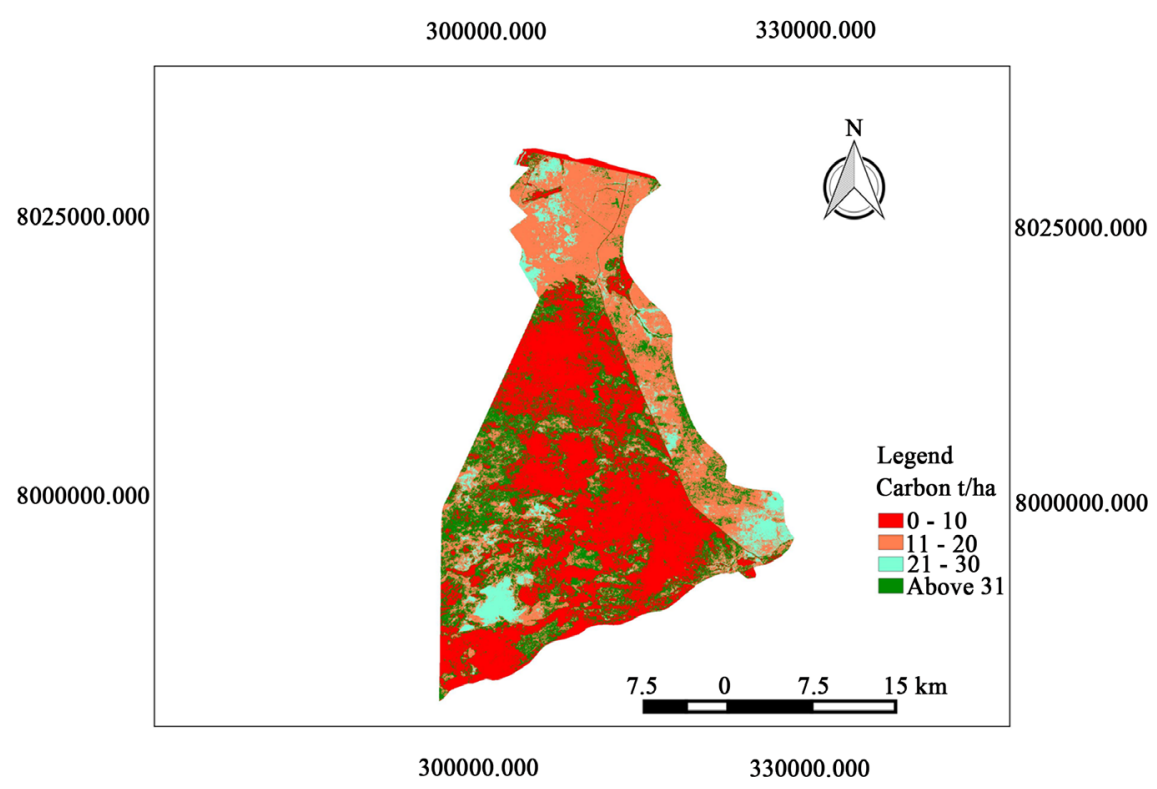

Figure 5. Map showing above ground carbon stock for Kasane forest reserve in 2011.

because of shrubs and grasslands while low carbon is caused by mainly bare ground that is degraded land among other factors.

\subsection{Accuracy Assessment}

Carbon maps derived from classification of images usually contain some sort of errors due to several factors that range from classification techniques to methods of satellite data capture. Hence, evaluation of classification results is an important process in the classification procedure Yesserie (2009). The classification accuracy was performed in ENVI 5.3 using 50\% of AGC data from permanent plot (that were not used in the classification (Table 2). The overall accuracy was 97.8\%. According to Turan et al. (2010) the overall accuracy is acceptable as it is greater than conventional $80 \%$ therefore, indicates that there is good relationship between the AGC and NDVI (Table 2). This suggested that spectral data saturation is not a problem when using Landsat for biomass and carbon monitoring in Miombo woodlands. The use of high resolution imagery should provide more precise and accurate information but this should be at high cost (Gizachew et al., 2016). Medium resolution satellites have also been used to map carbon in other countries with relatively high accuracy (Gizachew et al., 2016).

\section{Conclusion}

The findings of the present study show that field data acquired through ground survey can be successfully combined with freely available satellite imagery to estimate carbon for a larger area and provide spatially explicit maps useful for management, planning, and reporting purposes. The approach presented in the study can be applied to map carbon stock of forest with similar biophysical properties. 
Table 2. The confusion matrix showing accuracy of each class.

\begin{tabular}{cccccc}
\hline Class & $\mathbf{0 - 2 0}$ & $\mathbf{2 1 - 4 0}$ & $\mathbf{4 1 - 6 0}$ & Above-61 & Total \\
\hline Unclassified & 0.00 & 0.00 & 0.00 & 0.00 & 0.00 \\
$0-20$ & 99.31 & 0.00 & 0.00 & 0.45 & 57.29 \\
$21-40$ & 0.00 & 96.77 & 2.43 & 8.04 & 18.40 \\
$41-60$ & 0.00 & 0.75 & 97.57 & 0.00 & 14.37 \\
Above-61 & 0.69 & 2.49 & 0.00 & 91.52 & 9.93 \\
Total & 100.00 & 100.00 & 100.00 & 100.00 & 100.00 \\
\hline
\end{tabular}

\section{Acknowledgements}

We would like to thank Keletso Mike Seabo and Ephraim Kagiso, who provided shapefiles for the research. Appreciation also goes to Boiki Ramatho, who helped in rereading this write-up. We also thank the Department of Forestry and Range Resources of Botswana for provision of the secondary field data for this project.

\section{Conflicts of Interest}

The authors declare that there is no conflict of interests regarding the publication of this paper.

\section{References}

Brown, S., Sathaye, J., Cannell, M., Kauppi, P., Burschel, P., Grainger, A., Heuveldop, J., Leesman, R., Moura Costa, R., \& Pinard, M. (2005). Management of Forests for Mitigation of Greenhouse Gas Emissions. Berkeley, CA: Ernest Orlando Lawrence Berkeley National Laboratory.

Dixon, R., Brown, S., Houghton, R., Soiomon, A., Trexier, M., \& Wisniewski, J. (1994). Carbon Pools and Flux of Global Forest Ecosystems. Science, 263, 14.

Gizachew, B., Solberg, S., Næsset, E., \& Mauya, E. (2016). Mapping and Estimating the Total Living Biomass and Carbon in Low-Biomass Woodlands Using Landsat 8 CDR Data. Carbon Balance Manage, 11, 13.

Glenday, J. (2008). Carbon Storage and Emissions Offset Potential in an African Dry Forest, the Arabuko-Sokoke Forest, Kenya. Environmental Monitoring and Assessment, 142, 85-95.

Hall, R. J., Case, B. B., Arsenault, E., Price, D. T., Luther, J. E., Piercey, D. E., Fournier, R. A., \& Guindon, L. (2002). Modeling and Mapping Forest Biomass Using Forest Inventory and Landsat TM Data: Results from the Foothills Model Forest, Alberta. In Proceedings of the International Geoscience and Remote Sensing Symposium and 24th Canadian Symposium on Remote Sensing (CD-ROM). Toronto: IEEE.

Malimbwi, R. E., Eid, T., \& Chamshama, S. A. O. (2016). Allometric Tree Biomass and Volume Models in Tanzania (pp. 19-31). Morogoro: Department of Forest Mensuration and Management, Tanzania.

Matsushita, B., Yang, W., Chen, J., Onda, Y., \& Qiu, G. (2007). Sensitivity of the Enhanced Vegetation Index (EVI) and Normalized Difference Vegetation Index (NDVI) to Topographic Effects: A Case Study in High-Density Cypress Forest. Sensors, 7, 2636-2651. 
National Forest Resources Monitoring and Assessment of Tanzania-NAFORMA (2010). Field Manual Biophysical Survey. Dar es Salaam: Forest and Beekeeping Division.

Turan, S. O., Kodiogullari A. I., \& Gunlu, A. (2010). Spatial and Temporal Dynamics of Land Use Pattern Response to Urbanization in Kastamonu. African Journal of Biotechnology, 9, 640-647.

Vafaei, S., Soosani, J., Adeli, K., Fadaei, H., Naghavi, H., Pham, T. D., \& Tien Bui, D. (2018). Improving Accuracy Estimation of Forest Aboveground Biomass Based on Incorporation of ALOS-2 PALSAR-2 and Sentinel-2A Imagery and Machine Learning: A Case Study of the Hyrcanian Forest Area (Iran). Remote Sensing, 10, 172.

Wulder, M., \& Franklin, S. (eds.) (2003). Remote Sensing of Forest Environments: Concepts and Case Studies. Dordrecht, Boston, London: Kluwer Academic Publishers.

Yesserie, A. G. (2009) Spatio-Temporal Land Use/Land Cover Changes Analysis and Monitoring in the Valencia Municipality, Spain (p. 69). Dissertation for Award of MSc Degree, Castellón: Universitat Jaume I. 